\title{
Imaging of Pancreatitis in Children
}

\author{
Chomanad Chittchang, M.D. ${ }^{1,2}$, Bernard F. Laya, M.D. ${ }^{3}$, Supika Kritsaneepaiboon, M.D. ${ }^{1}$ \\ 'Department of Radiology, Faculty of Medicine, Prince of Songkla University, Hat Yai, Songkhla 90110, Thailand. \\ ${ }^{2}$ Section of Radiology, Samitivej Srinakarin Hospital, Suan Luang, Bangkok 10250, Thailand. \\ ${ }^{3}$ Institute of Radiology, St. Luke's Medical Center Quezon City and Global City, Department of Radiology, St. Luke's Medical \\ Center College of Medicine - William H. Quasha Memorial, Quezon City 1112, Philippines. \\ Received 12 January 2021 • Revised 6 February 2021 • Accepted 10 February 2021 • Published online 27 May 2021
}

\begin{abstract}
:
Pancreatitis in children has become more recognized over the past decade. Recent studies published by the INSPPIRE (INternational Study Group of Pediatric Pancreatitis: In Search for a CuRE) Group categorizes pediatric pancreatitis according to various etiologies and clinical course of disease in acute pancreatitis (AP), acute recurrent pancreatitis (ARP) and chronic pancreatitis. Imaging modalities help fulfill the diagnosis of AP in cases of atypical clinical context, while imaging also completes the major diagnostic criteria in CP. Ultrasound is the modality of choice to evaluate children with AP. Computed tomography should be reserved to assess the severity of complicated AP, or in the acute traumatic setting due to radiation concerns in children. Magnetic resonance cholangiopancreatography is used for the evaluation of underlying pancreaticobiliary structural abnormalities and for diagnosing CP. The etiologies of pediatric pancreatitis are diverse and unique including biliary stones, pancreaticobiliary structural abnormalities, genetic mutationrelated, drugs, trauma, systemic diseases and autoimmune-related cause. This article provides a pictorial review of the imaging modalities and findings related to the clinical course and etiologies of pediatric pancreatitis (AP, ARP and CP).
\end{abstract}

Keywords: children, computed tomography, magnetic resonance cholangiopancreatography, pancreatitis, ultrasound

Contact: Supika Kritsaneepaiboon, M.D.

Department of Radiology, Faculty of Medicine, Prince of Songkla University,

Hat Yai, Songkhla 90110, Thailand.

E-mail: supikak@yahoo.com

J J H H

This is an open access article under the CC BY-NC-ND license

(http://www.jhsmr.org/index.php/jhsmr/about/editorialPolicies\#openAccessPolicy).

J Health Sci Med Res 2022;40(1):95-109 doi: $10.31584 / j h s m r .2021812$ www.jhsmr.org 


\section{Introduction}

An increasing incidence of acute pancreatitis (AP) in pediatric patients has been evident over the past three decades. ${ }^{1-5}$ Pancreatitis has been reported in all pediatric age groups with no significant sex differences in any of the age groups. ${ }^{1,3,4}$ The INSPPIRE (INternational Study Group of Pediatric Pancreatitis: In Search for a CuRE) Group has categorized AP, acute recurrent pancreatitis (ARP), and chronic pancreatitis $(\mathrm{CP})$ based on the natural history of the disease. ${ }^{6,7}$ Studies have reported that $12.2-34.5 \%$ of children with AP have recurrence of the disease. ${ }^{3,8,9}$ The incidences of ARP and CP are in children, however, both ARP and CP in children are believed to be a disease continuum, and both show strong associations with genetic mutations and involve substantial disease burden. ${ }^{10-12}$ This article provides a pictorial review of imaging modalities and findings related to the clinical course and various etiologies of pediatric pancreatitis (AP, ARP and CP) based on cases at our institution.

\section{Imaging modalities}

Based on the INSPPIRE diagnostic criteria for pancreatitis, imaging findings help fulfill the diagnosis of AP in cases of atypical clinical context, while completing the major diagnostic criteria for $\mathrm{CP}$, to avoid the risk of performing an unnecessary pancreatic biopsy. Imaging modalities are also able to give a better picture of the severity and complications of AP. As a rule of thumb, the higher the grade of pancreatitis, the more likely it is for complications to occur. AP complications vary from local to systemic complications such as, systemic inflammatory response, disseminated intravascular coagulopathy and/ or organ failure. The local complications which can be assessed by imaging include acute fluid collections, pseudocysts, abscesses, pancreatic/peripancreatic necrosis, disconnected ducts, renal, splenic, or portal vein thrombosis, and splenic and/or gastroduodenal pseudoaneurysm. ${ }^{13}$

\section{Plain radiography}

The plain radiograph AP findings are nonspecific including localized bowel ileuses. Certain findings such as a Colon Cutoff sign are suggestive. ${ }^{14}$ Upper abdominal calcifications such as pancreatic parenchymal calcifications, gallstones or biliary tract stones may also be present. ${ }^{15}$

\section{Ultrasound (US)}

US is usually the first imaging modality utilized to assess children with suspected AP due to the lack of ionizing radiation and without sedation required. ${ }^{15}$ The reliable US findings in AP are enlarged pancreatic size and pancreatic duct dilatation. ${ }^{16-18}$ The cut-off diameter of the dilated pancreatic duct to indicate AP is age-matched, as more than $1.5 \mathrm{~mm}$ in 1-6 years of age, $>1.9 \mathrm{~mm}$ in 7-12 years of age and $>2.2 \mathrm{~mm}$ in 13-18 years of age are associated with the presence of $\mathrm{AP} .{ }^{18}$ Pancreatic echogenicity is unreliable for detecting AP. ${ }^{16}$ In cases of CP, the sonographic hallmarks include pancreatic calcifications, glandular atrophy, fatty replacement and/or fibrosis. ${ }^{19}$ US is also helpful in detecting choledochal cysts (CC), gallstones, and pseudocyst formation with a high degree of sensitivity $(92.0 \%) .^{20}$ The overall sensitivity of US in detecting AP in pediatric patients is only $52.0-57.0 \% .^{21,22}$ The main limitation of pancreatic US is bowel gas can obscure the pancreas. ${ }^{23}$ Another modality is endoscopic US (EUS), which offers diagnostic and therapeutic interventions. ${ }^{24}$

\section{Computed tomography (CT)}

Contrast enhanced CT (CECT) provides $78.0 \%$ sensitivity in detecting pancreatitis. ${ }^{21}$ CECT is recommended in cases of AP with atypical or delayed presentation. CECT 
can detect pancreatic necrosis, pancreatic pseudocysts, and underlying biliary disease or anatomic abnormalities. ${ }^{25}$ Balthazar et al. developed a computed tomography severity index (CTSI) based on the appearance of the pancreas and the extent of necrosis in the setting of AP. ${ }^{26}$ The CTSI is superior to clinical scoring systems for early recognition of the complications and mortality in AP patients (sensitivity $81.0 \%$, specificity $76.0 \%$, positive predictive value $62.0 \%$, negative predictive value $90.0 \%) .{ }^{27}$ Concordance between the CTSI and revised Atlanta classification for pediatric AP severity is still controversial, particularly in severe pancreatitis. ${ }^{28,29}$ The main disadvantages of CECT in the pediatric population are difficulty in evaluating the ductal anatomy and radiation exposure..$^{30,31}$ Regarding the concern over radiation exposure, CECT is only recommended when the patient's clinical condition deteriorates or is persistently severe. $^{25}$

\section{Magnetic resonance imaging (MRI)/MR cholangio- pancreatography (MRCP) \\ MRI/MRCP provides improved visualization of} the biliary and pancreatic ductal anatomy, while avoiding radiation exposure. ${ }^{30}$ In $\mathrm{AP}, \mathrm{MRI}$ may be more sensitive than CECT in evaluating necrotic tissue..$^{30,32} \mathrm{MRCP}$ is able to detect the etiology of pancreatitis including bile duct stones, CC, and pancreaticobiliary anomalies. ${ }^{25,30}$ The detection rate for CC is $96.0 \%$ while the sensitivity, specificity, and accuracy for detecting ductal anomalies are $83.0 \%, 90.0 \%$, and $86.0 \%$, respectively. ${ }^{33}$ Sometimes the MRI may be limited due to extensive obscuring edema in AP. In CP, MRCP helps to demonstrate pancreatic duct abnormalities including dilatation, irregularities, or strictures and detect pancreatico-pleural fistula. ${ }^{12,30}$ The drawbacks of $\mathrm{MRI}$ are the long scanning time, sedation and its limitation in detecting the small caliber pancreaticobiliary ducts, especially in neonates and young infants. Manganese and ferrous concentrated oral contrast agents or pineapple or blueberry juices administered within 30 minutes before scanning have been suggested to improve pancreaticobiliary ductal visualization by reduction or elimination of the bright fluid signal intensity of any overlapping fluid-filled bowel. ${ }^{34-38}$

\section{Etiologies of pediatric pancreatitis}

The causes of pediatric pancreatitis are different from adults, in whom the usual causes are gallstones and alcohol consumption. The reported etiologies of AP in children are drugs, trauma, systemic disease, structural abnormalities such as CC and abnormal union of the pancreaticobiliary junction. The biliary causes and anatomic abnormalities are more frequent in Asian children while idiopathic and familial causes are more pronounced in Western children. ${ }^{39}$ It is now known that idiopathic and familial pancreatitis are most likely related to genetic mutations. ${ }^{40}$ It is important to diagnose $\mathrm{CP}$ in children because of long term pancreatic exocrine and endocrine insufficiencies as well as the higher risk for pancreatic malignancy. ${ }^{12,40}$ In pediatric ARP-CP patients, genetic factors account for about two-thirds of the underlying causes while obstructive lesions of the pancreas are responsible for the rest. ${ }^{40}$ The major etiologies of pediatric pancreatitis are discussed in detail following.

\section{Biliary Pancreatitis}

\section{Gallstones and bile duct stone}

Gallstone is an uncommon cause of AP in children and is found usually only in the presence of predisposing factors. ${ }^{41}$ Bile duct stones occur in $2.0-6.0 \%$ of children with gallstones, often in association with jaundice or pancreatitis or, and structural anomalies in the pancreaticobiliary system. ${ }^{41,42}$ US is the modality of choice for the detection of gallstones. ${ }^{41}$ CT or MRCP are also useful in detecting biliary stones. ${ }^{34}$ 


\section{Pancreaticobiliary structural abnormalities}

The incidences of pediatric AP concomitant with pancreaticobiliary structural abnormalities have been reported at $43.0 \%$ and $74.0 \%$ of cases. ${ }^{43,44}$ The spectrum of embryological malformations of the pancreaticobiliary ductal system causing pancreatitis includes anomalous pancreaticobiliary ductal union (APBDU), CC, and pancreatic divisum (PD).

APBDU is defined as a junction of the pancreatic duct and common bile duct located outside the duodenal wall, forming a long common channel (LCC). ${ }^{45}$ (Figure 1Figure 3). A common channel measuring more than 5 $\mathrm{mm}$ would be considered abnormal in children. ${ }^{45}$ Only 7.3\% of clinically diagnosed AP with APBDU cases had intraoperative evidence of pancreatic inflammation, the condition is probably caused by transient obstruction of an LCC or distal bile duct due to protein plugs. ${ }^{46}$ This most likely explains why most APs resolve spontaneously or improve after a short period of conservative treatment, as shown by radiographic findings. ${ }^{46}$ (Figure $2 A-D$, Figure $3 A-D$ ).

CC manifests as an abnormal disproportionate cystic dilatation of the bile ducts and is classified by Todani's classification. ${ }^{47}$ Although the pathophysiology of CC is still unclear, it is widely accepted that CC arises from an APBDU, particularly an LCC, which is seen in $50.0-80.0 \%$ of patients. ${ }^{48}$ The sphincter of Oddi (SO) cannot extend to cover the entire length of the LCC, thus allowing reflux of the pancreatic juice into the bile duct (Figure 1) and leading to consequent inflammation and weakening of the bile duct wall. ${ }^{49,50}$ For CC patients without an APBDU, the primary SO dysfunction accounts for the cause of $\mathrm{CC}^{50}$ Studies have found that in around half of the children with CC types la, Ic, IVa, or IVb, the CC were associated with an APBDU $^{51,52}$ (Figure 2A-D, Figure 3A-D). Because of the close relationship between APBDUs and CCs, both conditions share the same mechanism that leads to pancreatitis. $^{52}$
PD is the presence of a persistent accessory ampulla with the dorsal pancreatic duct that drains the major portion of the pancreas. This smaller ampulla is prone to obstruction and stenosis, which may result in pancreatitis ${ }^{34}$ (Figures 4A, B and C). However, the frequency of identified PD in pediatric ARP-CP patients (8.0-9.0\%) does not differ from the general population, and therefore, PD alone may not be causative of ARP-CP. Further investigations for other causes of ARP-CP are still warranted. ${ }^{41}$

MRCP has an important role in the detection APBDU, CC, and PD. The diagnostic accuracy of MRCP is $100 \%$ in patients with CC, while it ranges from $40.0-$ $80.0 \%$ in APBDU. ${ }^{49,53} \mathrm{CC}$ larger than $3 \mathrm{~cm}$ in size or with a large inferior extension can obscure the ampullary region and the SO spasms can cause an artificially short common channel. $^{54,55}$

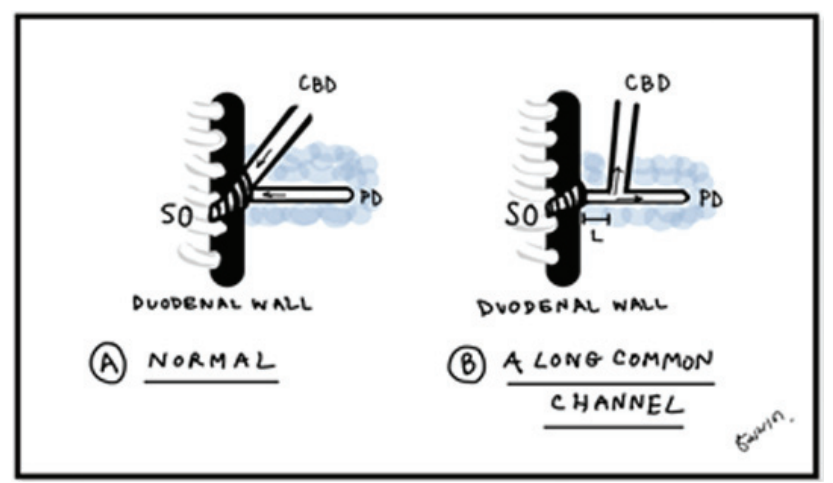

$\mathrm{CBD}=$ common bile duct, $\mathrm{SO}=$ Sphincter of Oddi, $\mathrm{PD}=$ pancreatic duct, $\mathrm{L}=$ long common channel, arrows=bile duct and pancreatic juice flow directions

Figure 1 Sphincter of Oddi

(A) Normal sphincter of Oddi covers both the common bile duct and pancreatic duct openings located in the duodenal wall. (B) Sphincter of Oddi cannot extend around the long common channel located outside the duodenal wall. 

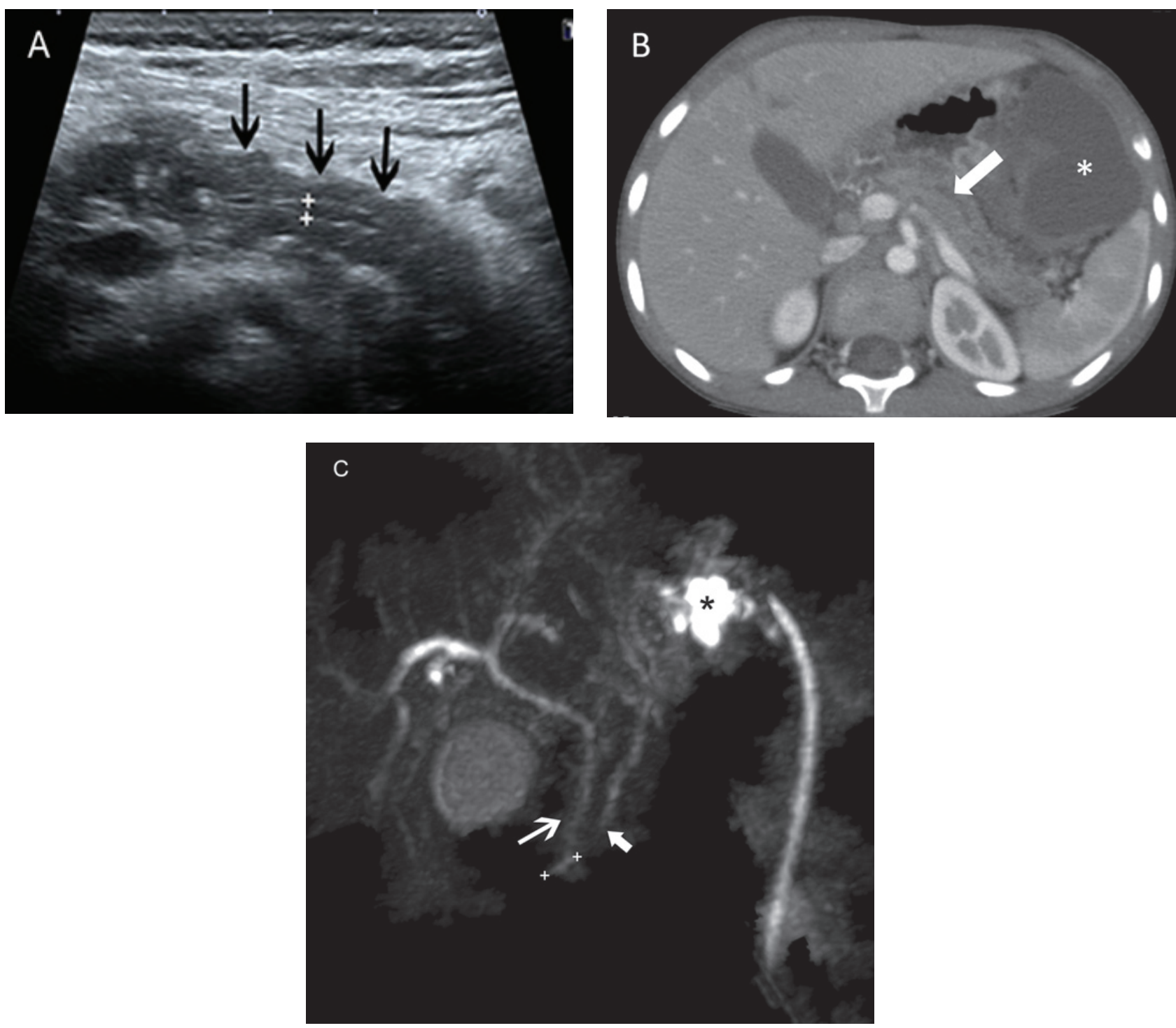

Figure 2 A 5-year-old girl with chronic pancreatitis due to anomalous pancreaticobiliary ductal union and nonstenotic long common channel. The patient's serum amylase was 359 U/L. (A) An US image shows pancreatic atrophy (arrows) and dilated pancreatic duct (cross-hairs). (B) An axial contrast-enhanced computed tomography shows pancreatic atrophy with dilated pancreatic duct (arrow) and pancreatic pseudocyst (asterisk). (C) A thick-slab magnetic resonance cholangiopancreatography image shows the pancreatic duct (thick arrow) and the common bile duct (thin arrow) joining into a 7-mm long, nondilated long common channel (cross-hairs). The asterisk shows a drainage catheter draining the pseudocyst. 

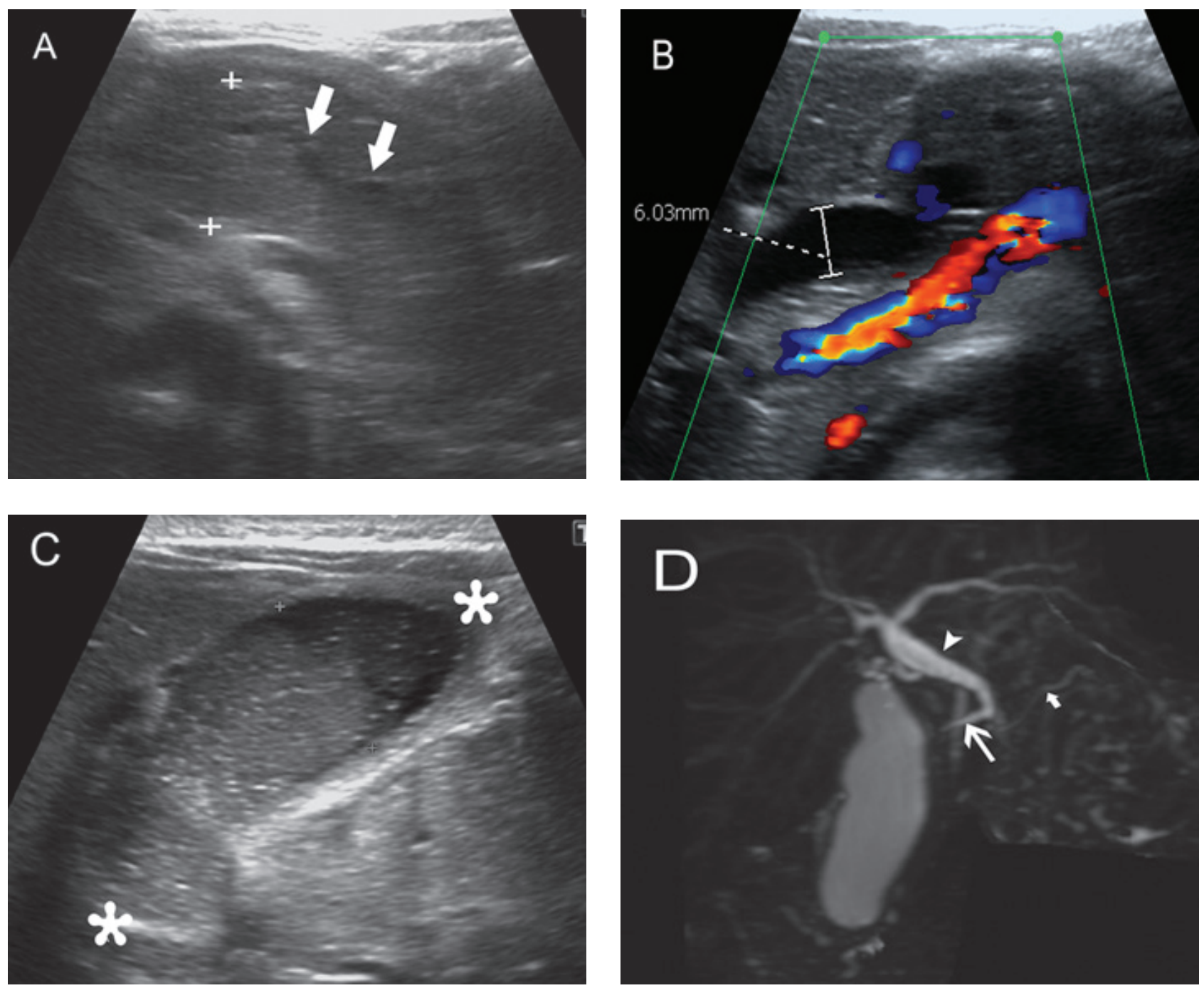

Figure 3 A 2-year-old girl with acute pancreatitis due to choledochal cyst type 1 and anomalous pancreaticobiliary ductal union and dilated long common channel. The patient's serum amylase was $367 \mathrm{U} /$ and serum lipase 2,918 U/. (A, B, C) Ultrasonographic images show diffusely enlarged pancreas (cross-hairs) with dilated main pancreatic duct (arrows), dilated common bile duct $(6 \mathrm{~mm})$, and thickened gallbladder wall with bile sludge (asterisks). (D) A maximum intensity projection 3-dimensional magnetic resonance cholangiopancreatography demonstrates fusiform dilatation of the common bile duct (arrowhead) joining with the nondilated pancreatic duct (short arrow) and the long common channel (long arrow) measuring 8-mm in length. 

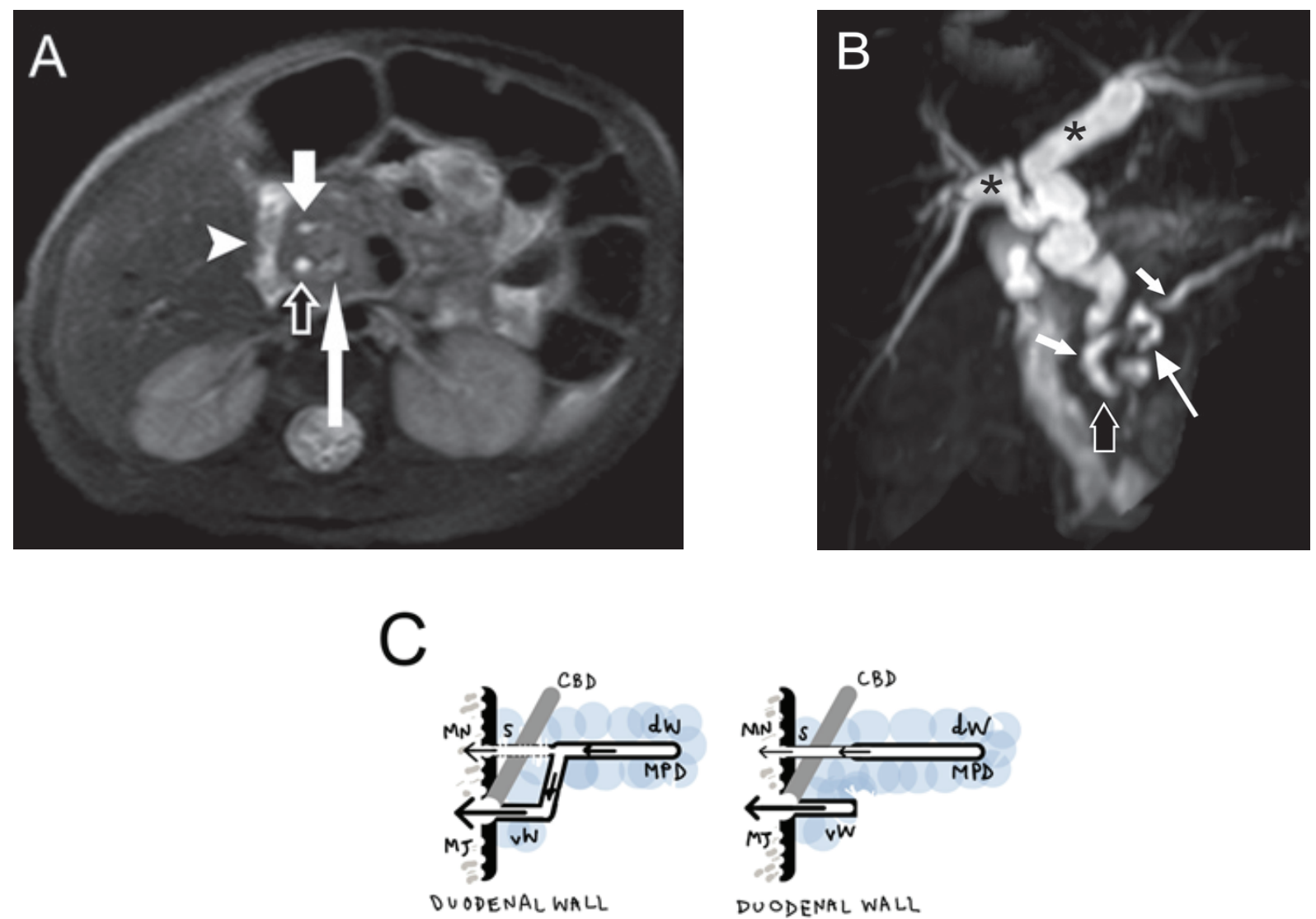

NORMAL

PANCREAS DIVSUM

$\mathrm{CBD}=$ common bile duct, $\mathrm{MN}=$ minor papilla, $\mathrm{MJ}=$ major papilla, $\mathrm{S}=$ duct of Santorini, $\mathrm{vW}=$ ventral duct of Wirsung, $d \mathrm{~W}=\mathrm{dorsal}$ duct of Wirsung, $\mathrm{MPD}=$ major pancreatic duct

Figure 4 A 2-year-old girl with AP due to pancreatic divisum and choledochal cyst type 4A. (A) An axial T2-weighted magnetic resonance image with fat saturation and (B) thick-slab magnetic resonance cholangiopancreatography image show parenchymal hyperintensity and peripancreatic fluid at the pancreatic head (arrowhead). Focal dilated duct of Santorini (otherwise known as the Santorinicele) (short white arrow) drains into the minor papilla while a bead-liked dilatation of the Dorsal duct of Wirsung (long white arrow) separately drains into the major papilla. Dilatation of the common bile duct (black arrow) and the proximal portion of right and left intrahepatic ducts (asterisks) can also be seen. (C) A picture illustrating the difference between normal pancreatic duct anatomy and pancreatic divisum. Normally, the main pancreatic duct is composed of the dorsal duct of the pancreatic body and a tail connected with the ventral duct of Wirsung at the pancreatic head and the uncinate process, then opening into the major papilla along with the common bile duct. The accessory duct of Santorini can be absent, or if present, will drain into the minor papilla. In pancreatic divisum, the major pancreatic duct drains via the smaller accessory duct of Santorini, then opens at the minor papilla, while the ventral duct of Wirsung separately opens at the major papilla without connecting with the main pancreatic duct. 


\section{Genetic mutation-related pancreatitis}

Recent studies have shown that pediatric ARP and $\mathrm{CP}$ patients are likely to have underlying genetic predispositions which were previously categorized as idiopathic or hereditary pancreatitis. The widely-known pancreatitis-related mutations include cystic fibrosis transmembrane conductance regulator, cationic trypsinogen (PRSS1), serine protease inhibitor Kazal-type 1 (SPINK1), chymotrypsin C (CTRC) and carboxypeptidase 1 (CPA1). ${ }^{40,55,56}$ The main pathophysiology of genetic mutation is that the pancreas is auto-digested by various mechanisms such as disturbing the normal trypsin pathway, lacking in dilution and alkalinization of the pancreatic secretions or inducing endoplasmic reticulum stress. ${ }^{39,57,58}$ Up to $80.0 \%$ of hereditary

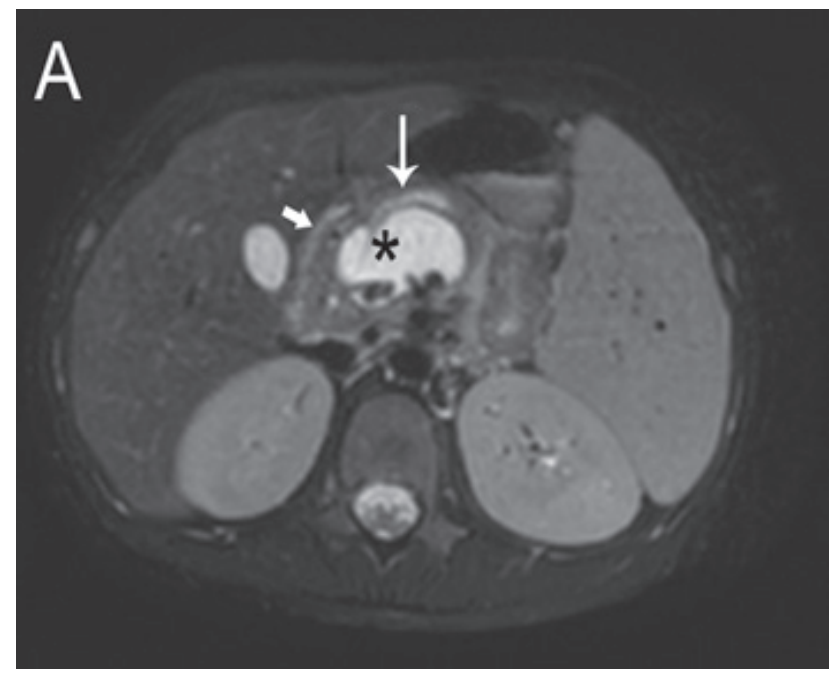

pancreatitis cases show PRSS1 mutation, while SPINK1 mutation is likely a disease modifier when concomitant with other genetic mutations and environmental factors. ${ }^{39,58,59}$ Imaging of genetic mutation-related pancreatitis depends on the stage of disease (Figure 5A-D). MRCP and genetic tests are recommended in every pediatric patient with ARP or lack of an obvious etiology of pancreatitis.

\section{Traumatic pancreatitis}

Blunt abdominal trauma is one of the leading causes of pediatric pancreatitis and pancreatic pseudocyst. Bicycle and vehicle injuries as well as sports injuries are common in children, and child abuse may result in pancreatitis in infants $^{60-62}$ The pancreas is vulnerable to crushing injury in

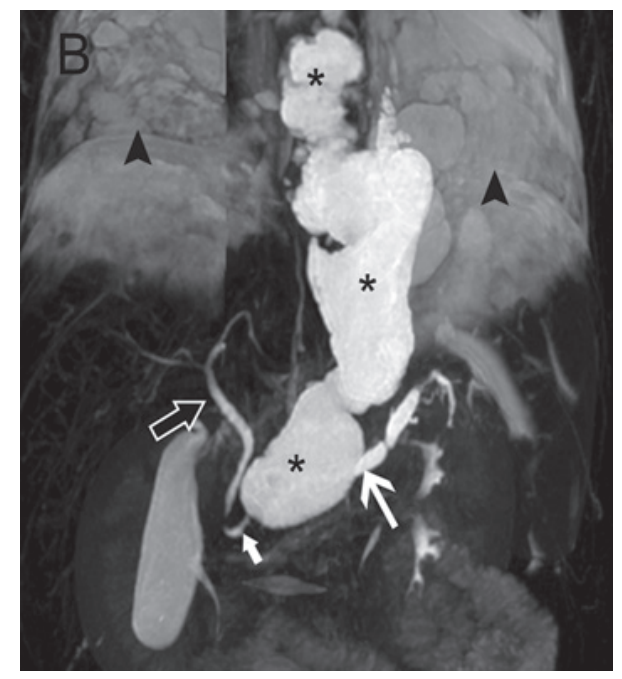

Figure 5 An 11-year-old boy with serine protease inhibitor Kazal-type 1 gene mutation-related chronic pancreatitis.

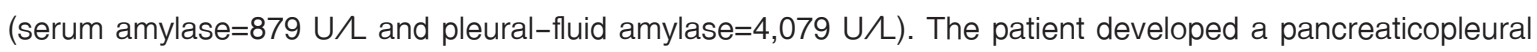
fistula and pancreatic pseudocyst with mediastinal extension as complications. (A) An axial T2-weighted image with fat saturation shows diffuse thinning of the pancreatic parenchyma (short arrow) with a dilated pancreatic duct (long arrow). A pancreatic pseudocyst (asterisk) with internal debris or bile sludge is also present. (B) A maximum intensity projection 3-dimensional magnetic resonance cholangiopancreatography demonstrates discontinuation of the non-dilated proximal pancreatic duct (short white arrow) and the dilated distal pancreatic duct (long white arrow), indicating pancreatic duct disruption. Mediastinal extension of the pseudocyst (asterisks) with bilateral pleural effusions (arrowheads) are also present. The common bile duct (dark arrow) is not dilated. 
blunt trauma due to impact against the adjacent vertebral column. ${ }^{61}$ Pancreatic injuries may result in death due to associated vascular injuries, and delayed morbidity and mortality. In the acute clinical setting, US and CT are the modalities of choice. Findings of acute pancreatic injuries in CT vary from enlarged edematous pancreas and parenchyma laceration/ fracture to pseudocysts (Figures 6A, B). MRCP is useful in evaluating pancreatic duct injuries. ${ }^{61}$

\section{Systemic causes of pancreatitis}

A long list of systemic diseases can attribute to AP, including Reye syndrome, systemic lupus erythematosus (SLE), polyarteritis nodosa, juvenile rheumatoid arthritis, sepsis, multiple organ failure, organ transplantation, hemolytic-uremic syndrome, Henoch-Schoenlein purpura, Kawasaki disease, inflammatory bowel disease, chronic intestinal pseudo-obstruction, gastric ulcer, anorexia nervosa, food allergy, cystic fibrosis, and infectious agents such as rotavirus and the varicella virus. ${ }^{39,62}$ Other systemic conditions such as burns (Figure 7A) or metabolic abnormalities including hypercalcemia, hypertriglyceridemia, diabetic ketoacidosis, and inborn errors of metabolism have also been found to be associated with AP. ${ }^{39}$ Most pediatric AP patients with systemic causes show complete recovery after conservative treatment and good control of the causative disease.

\section{SLE}

SLE-related pancreatitis can occur as early as the initial manifestation of SLE or during the active disease course (Figure 7B). The exact pathogenesis is not well understood but vascular complications from vascular injury or occlusion is one possibility. A diagnosis of SLErelated pancreatitis should be made only after excluding mechanical and toxic metabolic etiologies of pancreatitis such as hypertriglyceridemia or a medication-related cause. Corticosteroids are reported to be an effective treatment for SLE-related pancreatitis. ${ }^{63}$

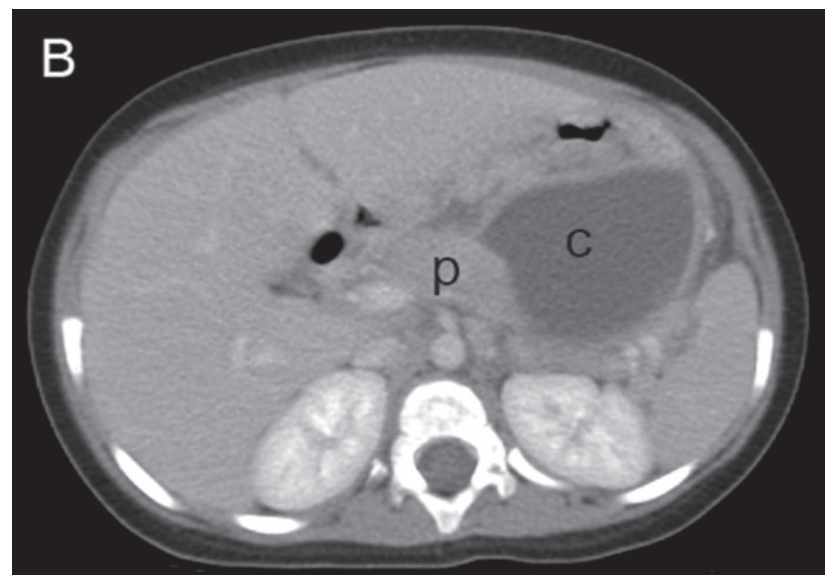

Figure 6 Different stages of pancreatic injuries. (A) A 7-year-old boy with acute pancreatic injury due to a motorcycle accident. (serum amylase=496 U $\mathbf{L}$ ). An axial contrast-enhanced computed tomography image shows a laceration at the pancreatic body and contusion at the pancreatic body-to-tail (short arrows). Peripancreatic hematoma and fluid can also be seen in the lesser sac (f). A splenic laceration (long arrow) is also present. (B) A 2-year-old girl with an occult pancreatic injury after a car accident 3 weeks earlier. A pancreatic pseudocyst $(c)$ is noted while the pancreas $(p)$ appears normal. 

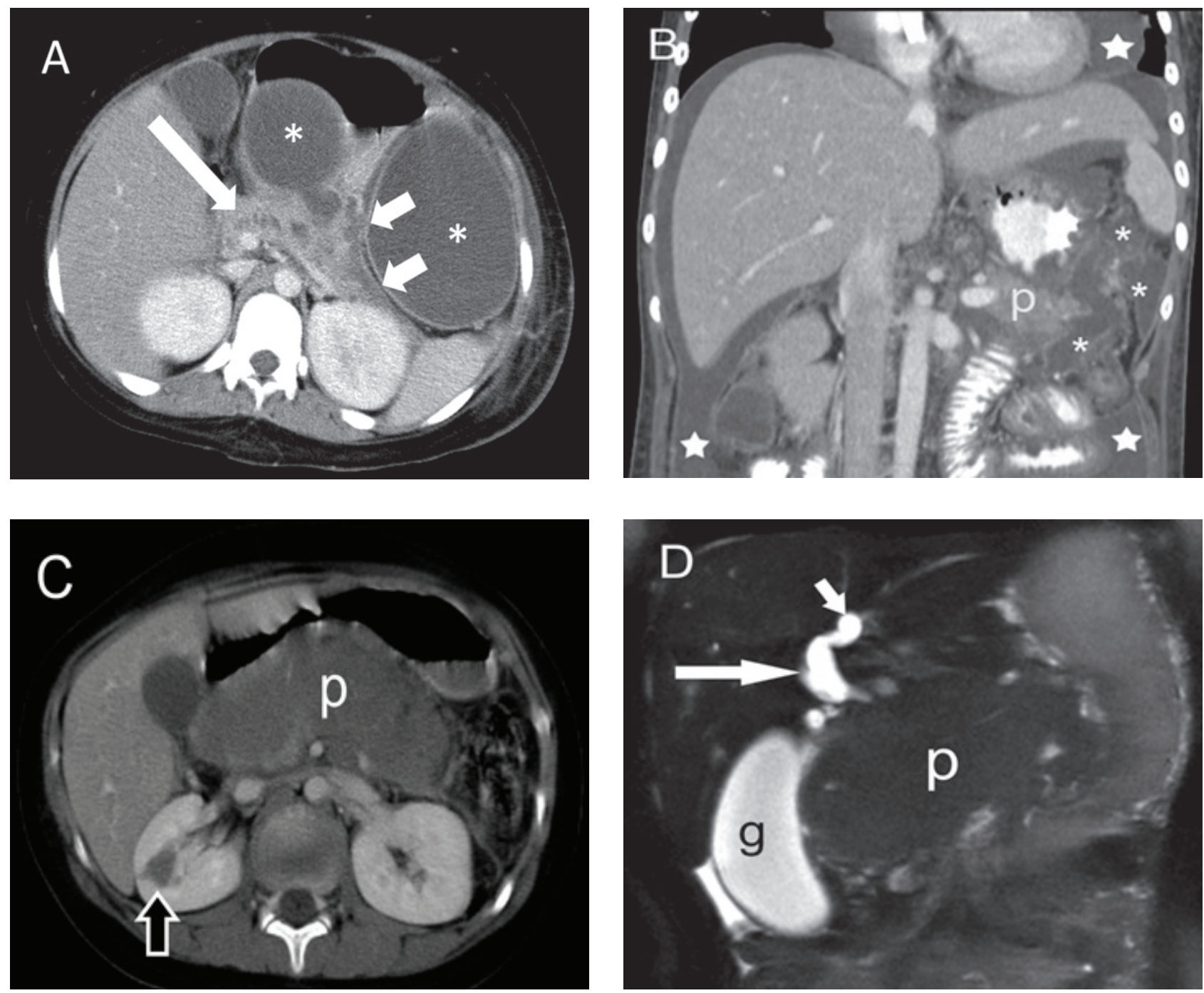

Figure 7 Systemic causes of pancreatitis (A) A12-year-old female developed acute pancreatitis during her admission in the intensive care unit due to $60.0 \%$ second to third degree burn. (serum amylase=90 U $/$, serum lipase $=154 \mathrm{U} /$ ). An axial contrast-enhanced computed tomography image shows multiple rim-enhancing fluid collections (asterisks) at the lesser sac and the left anterior pararenal space, with peripancreatic fluid (short arrows). The pancreatic duct (long arrow) is also dilated. (B) A 14-year-old girl with active systemic lupus erythematosus who presented with acute pancreatitis. An axial contrast-enhanced computed tomography shows multiple pseudocysts (asterisks) at the peripancreatic region. The pancreas ( $p$ ) is enlarged. Massive ascites and pericardial effusion (stars) are noted. (C, D) A 9-year-old boy with Burkitt's lymphoma mimicking acute pancreatitis. (serum amylase=758 U $/$, serum lipase=1,887 U $\mathbf{L}$ ). An axial contrast-enhanced computed tomography $(\mathrm{C})$ and coronal source image of magnetic resonance cholangiopancreatography (D) shows markedly enlarged pancreatic head and body (p) obstructing the distal common bile duct (long white arrow). Distended gallbladder (g) and dilated intrahepatic duct (short arrow) are also seen. Right renal involvement is seen as focal hypodensity (dark arrow). 


\section{Lymphoma}

Burkitt lymphoma, an aggressive B-cell nonHodgkin's lymphoma (NHL), has been reported to involve the pancreas in children. Only $0.2-2.0 \%$ of patients with $\mathrm{NHL}$ have pancreatic involvement at presentation, with diffuse large B-cell lymphoma as the predominant type. ${ }^{64}$ Imaging findings of pancreatic lymphoma can mimic AP including focal or diffuse enlargement of the pancreas and abnormal parenchymal lesion, which appears very hypoechoic in US, homogeneously hypodense in CT, and of intermediatesignal intensity in MRI. Peripancreatic inflammation can also be $\operatorname{seen}^{64,65}$ (Figure 7C, D).

\section{Drug-induced pancreatitis}

Several drugs can cause pancreatic toxicity, including $L$-asparaginase (L-Asp), steroids, valproic acid, azathioprine, mercaptopurine, mesalazine, cytarabine, salicylic acid, indomethacin, tetracycline, chlorothiazide, isoniazid, anticoagulant drugs, borate, and alcohol. Druginduced pancreatitis particularly affects in children with acute lymphoblastic leukemia (ALL) receiving L-Asp therapy, with a higher incidence ranging from $2.0-16.0 \% .^{39}$ One study reported a higher mortality rate in children with $A L L$ who had AP than those without AP (43.8\% vs. $19.3 \%$, respectively). ${ }^{66}$ Drug-induced pancreatitis also demonstrates a wide spectrum of disease manifestations, from subclinical AP to fatal hemorrhagic pancreatitis $\mathrm{AP}^{34}$ (Figure 8). Recurrence of pancreatitis has been reported in up to $63.0 \%$ of patients following re-exposure to L-Asp. ${ }^{67}$

\section{Autoimmune pancreatitis}

Autoimmune pancreatitis is defined by marked fibrosis and the infiltration of clusters of differentiation 4-positive T-lymphocytes and immunoglobulin G4 (IgG4)-positive plasma cells around the pancreatic duct. ${ }^{34}$ Autoimmune pancreatitis is increasingly encountered in adults, but a few cases have also been reported in children and adolescents. ${ }^{68}$ Common imaging findings include focal or diffuse enlargement of the pancreas, peripancreatic hypodense or hypointense rim on contrast-enhanced CT or MRI, as well as bile duct dilatations and strictures. ${ }^{34,68}$ Improvement of radiographic findings of AP after steroid therapy may indicate autoimmune pancreatitis. ${ }^{34}$

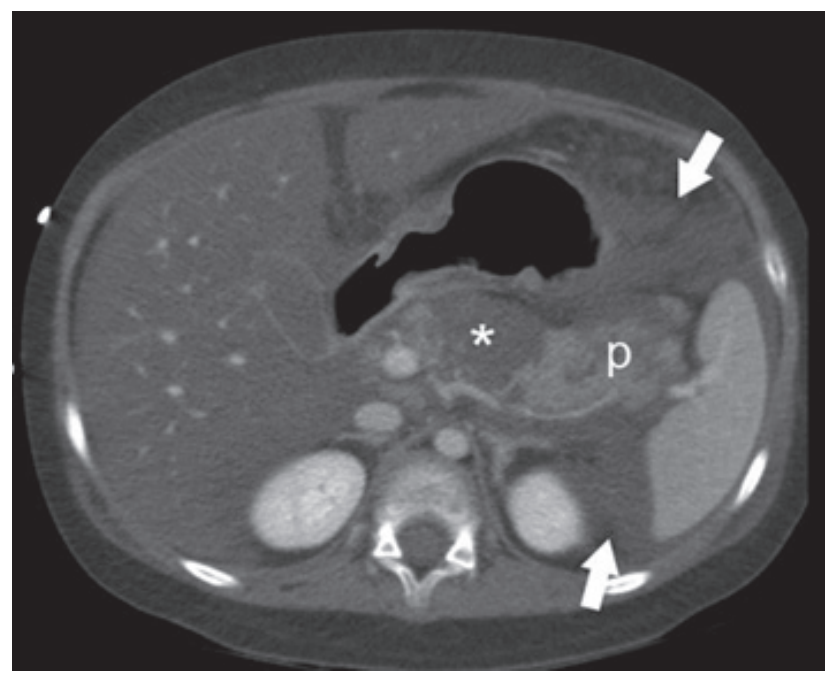

Figure 8 An 11-year-old-girl with underlying acute lymphoblastic leukemia, B-cell type developed L-Asparaginase- induced acute pancreatitis. (serum amylase $=860 \mathrm{U} /$ and serum lipase $=2,586$ U/). An axial contrast-enhanced computed tomography image shows diffusely edematous pancreas ( $p)$ with focal non-enhanced necrotic tissue (asterisk), compatible with acute necrotizing pancreatitis. Peripancreatic fluid (arrow) is also seen.

\section{Infectious disease associated pancreatitis}

Various infectious agents including viruses (mumps, varicella-zoster virus, coxsackievirus, cytomegalovirus, hepatotropic virus, human immunodeficiency virus, herpes simplex virus, hepatitis A virus and other viruses); bacteria (mycoplasma, salmonella, legionella, and leptospira); fungi (aspergillus); and parasites (toxoplasmosis, cryptosporidium, 
and ascaris) have been implicated as the cause of pancreatitis in about $10.0 \%$ of all pancreatitis cases. ${ }^{39,69,70}$ However, we still lack evidence as to whether treating the infectious process will improve the clinical outcome. AP has also been reported after viral vaccines such as Mumps, Mumps-Measles-Rubella and Hepatitis A and B. ${ }^{71}$

\section{Conclusion}

Pediatric pancreatitis is classified into AP and ARP-CP by the INSPPIRE Group. Imaging modalities play an important role in the assessment of severity and complications in pediatric $\mathrm{AP}$, and imaging findings have become the diagnostic criteria in pediatric CP. The etiologies of pediatric pancreatitis are diverse and unique.
The algorithm for evaluation of and approach to pancreatitis in children categorized by clinical subgroups is shown in the diagram 1. Knowledge regarding the natural history of pediatric pancreatitis and the appropriate imaging investigation are important in achieving prompt and proper management of children with pancreatitis.

\section{Funding sources}

This research was supported by a grant from the Faculty of Medicine, Prince of Songkla University.

\section{Conflict of interest}

The authors declare that there are no conflicts of interest.

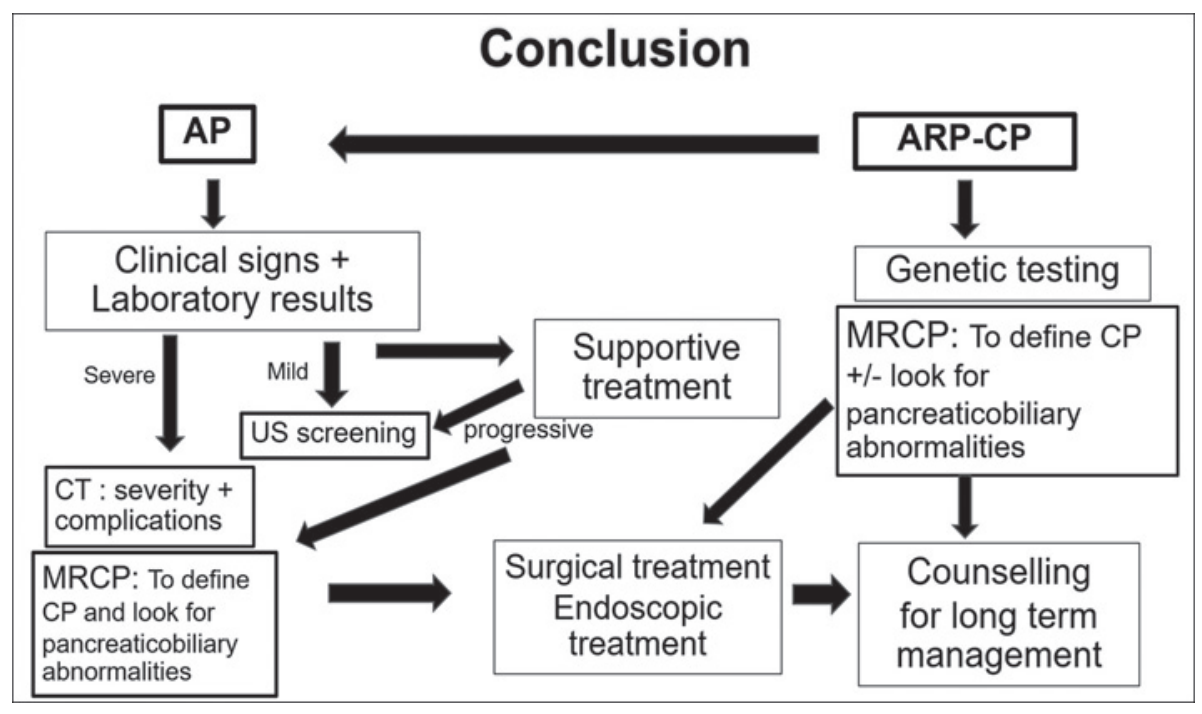

$\mathrm{AP}=$ acute pancreatitis, $\mathrm{ARP}=$ acute recurrent pancreatitis, $\mathrm{CP}=$ chronic pancreatitis, $\mathrm{MRCP}=\mathrm{MR}$ cholangiopancreatography, US=ultrasound, $\mathrm{CT}=$ computed tomography)

Diagram 1 Diagrammatic summary of the steps for evaluation of and approach to pediatric pancreatitis categorized by clinical subgroups. 


\section{References}

1. Nydegger A, Heine RG, Ranuh R, Gegati-Levy R, Crameri J, Oliver MR. Changing incidence of acute pancreatitis: 10-year experience at the Royal Children's Hospital, Melbourne. J Gastroenterol Hepatol 2007;22:1313-6.

2. Morinville VD, Barmada MM, Lowe ME. Increasing incidence of acute pancreatitis at an American pediatric tertiary care center: is greater awareness among physicians responsible? Pancreas 2010;39:5-8.

3. Park A, Latif SU, Shah AU, Tian J, Werlin S, Hsiao A, et al. Changing referral trends of acute pancreatitis in children: a 12-year single-center analysis. J Pediatr Gastroenterol Nutr 2009;49:316-22.

4. Cheng YJ, Yang HY, Tsai CF, Lin JS, Lee HC, Yeung CY, et al. Epidemiology of pediatric acute pancreatitis in Taiwan: a nationwide population based study. J Pediatr Gastroenterol Nutr 2019;68:e7-12.

5. Corfield AP, Cooper MJ, Williamson RC. Acute pancreatitis: a lethal disease of increasing incidence. Gut 1985;26:724-9.

6. Morinville VD, Husain SZ, Bai H, Durie PR, Freedman SD, Himes R, et al. Definitions of pediatric pancreatitis and survey of current clinical practices. J Pediatr Gastroenterol Nutr 2012;55:261-5.

7. Uc A, Perito ER, Pohl JF, Shah U, Abu-El-Haija M, Barth B, et al. International study group of pediatric pancreatitis: in search for a cure. Cohort study: design and rationale for INSPPIRE 2 from the consortium for the study of chronic pancreatitis, diabetes, and pancreatic cancer. Pancreas 2018;47:1222-8.

8. Sanchez-Ramirez CA, Larrosa-Haro A, Flores-Martinez S, Sanchez-Corona J, Villa-Gomez A, Macias-Rosales R. Acute and recurrent pancreatitis in children: etiological factors. Acta Paediatr 2007;96:534-7.

9. Werlin SL, Kugathasan S, Frautschy BC. Pancreatitis in children. J Pediatr Gastroenterol Nutr 2003;37:591-5.

10. Spanier B, Bruno MJ, Dijkgraaf MG. Incidence and mortality of acute and chronic pancreatitis in the Netherlands: a nationwide record-linked cohort study for the years 19952005. World J Gastroenterol 2013;19:3018-26.

11. Kumar S MD, Ooi CY, Werlin S, Abu-El-Haija M, Barth B, Bellin MD, et al. Pediatric acute recurrent and chronic pancreatitis. JAMA Pediatr 2016;170:562-9.
12. Schwarzenberg SJ, Bellin M, Husain SZ, Ahuja M, Barth B, Davis $\mathrm{H}$, et al. Pediatric chronic pancreatitis is associated with genetic risk factors and substantial disease burden. J Pediatr 2015;166:890-6.

13. O'Connor OJ, Buckley JM, Maher MM. Imaging of the complications of acute pancreatitis. Am J Roentgenol 2011: 197:W375-81.

14. Pickhardt PJ. The colon cutoff sign. Radiology 2000;215:387-9.

15. Parker BR. The pancreas. In: Kuhn JP, Slovis TL, Haller JO, editors. Caffey's Pediatric Diagnostic Imaging. $10^{\text {th }} \mathrm{ed}$. Pennsylvania: Mosby; 2004;p.1527-36.

16. Seigel MJ, Martin KW, Worthington JL. Normal and abnormal pancreas in children: US studies. Radiology 1987;165:15-8.

17. Jeffry RB Jr. Sonography in acute pancreatitis. Radiol Clin North Am 1989;27:5-17.

18. Chao HC, Lin SJ, Kong MS, Kuo CC. Sonographic evaluation of the pancreatic duct in normal children and children with pancreatitis. J Ultrasound Med 2000;19:757-63.

19. Seigel MJ, Chung EM. Adrenal glands, pancreas, and other retroperitoneal structures. In: Seigel MJ, editor. Pediatric Sonography. $4^{\text {th }}$ ed. Philadelphia: Lippincott Williams \& Wilkins; 2011;p.461-504.

20. Chang YJ, Chao HC, Kong MS, Hsia SH, Lai MW, Yan DC. Acute pancreatitis in children. Acta Paediatr 2011;100:740-4.

21. Chen CF, Kong MS, Lai MW, Wang CJ. Acute pancreatitis in children: 10-year experience in a medical center. Acta Paediatr Taiwan 2006;47:192-6.

22. Orkin SH, Trout AT, Fei L, Lin TK, Nathan JD, Thompson T, et al. Sensitivity of biochemical and imaging findings for the diagnosis of acute pancreatitis in children. J Pediatr 2019;213: 143-8.

23. Vaughn DD, Jabra AA, Fishman EK. Pancreatic disease in children and young adult: evaluation with CT. Radiographics 1998;18: 1171-7.

24. Lin TK, Troendle DM, Wallihan DB, Barth B, Fox VL, Fishman $\mathrm{DS}$, et al. Specialized imaging and procedures in pediatric pancreatology: a North American society for pediatric gastroenterology, hepatology, and nutrition clinical report. J Pediatr Gastroenterol Nutr 2017;64:472-4.

25. Abu-El-Haija M, Kumar S, Quiros JA. The Management of acute Pancreatitis in the pediatric population: a clinical report from the NASPGHAN Pancreas Committee. J Pediatr Gastroenterol Nutr 2018;66:159-6. 
26. Balthazar EJ, Robinson DL, Megibow AJ, Ranson JH. Acute pancreatitis: value of CT in establishing prognosis. Radiology 1990;174:331-6.

27. Lautz TB, Turkel G, Radhakrishnan J, Wyers M, Chin AC. Utility of the computed tomography severity index (Balthazar score) in children with acute pancreatitis. J Pediatria Surg 2012;47:1185-91.

28. Izquierdo YE, Fonseca EV, Moreno LÁ, Montoya RD, Guerrero Lozano R. Utility of CT classifications to predict unfavorable outcomes in children with acute pancreatitis. Pediatr Radiol 2018;48:954-61.

29. Li W, Luo S, Zhu Y, Shu M, Wen Y, Wang Z, et al. Concordance of the Balthazar Grade and the Revised Atlanta Classification: Proposing a Modified Balthazar Grade to Predict the Severity of Acute Pancreatitis in Pediatric Population. Pancreas 2018;47:1312-6.

30. Thai TC, Riherd DM, Rust KR. MRI manifestations of pancreatic disease, especially pancreatitis in the pediatric population. Am J Roentgenol 2013;201:W877-92.

31. Pema D, Kritsaneepaiboon S. Radiation dose from computed tomography scanning in patients at Songklanagarind Hospital: diagnostic reference levels. J Health Sci Med Res 2020;38:135-43.

32. Barral M, Taouli B, Guiu B, Koh DM, Luciani A, Manfredi R, et al. Diffusion-weighted MR imaging of the pancreas: current status and recommendations. Radiology 2015;274:4563.

33. Park DH, Kim MH, Lee SK, Lee SS, Choi JS, Lee YS, et al. Can MRCP replace the diagnostic role of ERCP for patients with choledochal cysts?. Gastrointest Endosc 2005;62:360-6.

34. Hwang JY, Yoon HK, Kim KM. Characteristics of pediatric pancreatitis on magnetic resonance cholangiopancreatography. Pediatr Gastroenterol Hepatol Nutr 2015;18:73-84.

35. Restrepo R, Hagerott HE, Kulkarni S, Yasrebi M, Lee EY. Acute pancreatitis in pediatric patients: demographics, etiology, and diagnostic imaging. Am J Roentgenol 2016;206:632-44.

36. Chavhan GB, Babyn PS, Manson D, Vidarsson L. Pediatric MR cholangiopancreatography: principles, technique, and clinical applications. Radiographics 2008;28:1951-62.

37. Frisch A, Walter TC, Hamm B, Denecke T. Efficacy of oral contrast agents for upper gastrointestinal signal suppression in MRCP: A systematic review of the literature. Acta Radiol Open 2017. doi: 10.1177/2058460117727315.

38. Marugami N, Takewa M, Iwaki Y, Hazeyama Y, Iwato K,
Takahama J, et al. MR signal changes on hepatobiliary imaging after oral ingestion of manganese chloride tetrahydrate: preliminary examination. Jpn J Radiol 2013;31: 713-23.

39. Suzuki M, Sai JK, Shimizu T. Acute pancreatitis in children and adolescents. World J Gastrointest Pathophysiol 2014;5: 416-26.

40. Gariepy CE, Heyman MB, Lowe ME, Pohl JF, Werlin SL, Wilschanski $\mathrm{M}$, et al. The causal evaluation of acute recurrent and chronic pancreatitis in children: consensus from the INSPPIRE group. J Pediatr Gastroenterol Nutr 2017;64: 95-103.

41. Sutton R, Cheslyn-Curtis S. Acute gallstone pancreatitis in childhood. Ann R Coll Surg Engl 2001;83:406-8.

42. Choi BH, Lim YJ, Yoon CH, Kim EA, Park YS, Kim KM. Acute pancreatitis associated with biliary disease in children. J Gastroenterol Hepatol 2003;18:915-21.

43. Fujishiro J, Masumoto K, Urita Y, Shinkai T, Gotoh C. Pancreatic complications in pediatric choledochal cysts. J Pediatr Surg 2013;48:1897-902.

44. Okada A, Higaki J, Nakamura T, Fukui Y, Kamata S. Pancreatitis associated with choledochal cyst and other anomalies in childhood. Br J Surg 1995;82:829-32.

45. Guelrud M, Morera C, Rodriguez M, Prados JG, Jaén D. Normal and anomalous pancreaticobiliary union in children and adolescents. Gastrointestinal endoscopy 1999;50:189-93.

46. Urushihara N, Hamada Y, Kamisawa T, Fujii H, Koshinaga T, Morotomi $Y$, et al. Classification of pancreaticobiliary maljunction and clinical features in children. $J$ Hepatobiliary Pancreat Sci 2017;24:449-55.

47. Todani T, Watanabe Y, Narusue M, Tabuchi K, Okajima K. Congenital bile duct cysts: classification, operative procedures, and review of thirty-seven cases including cancer arising from choledochal cyst. Am J Surg 1977;134:263-9.

48. Bhavsar MS, Vora HB, Giriyappa VH. Choledochal cysts: a review of literature. Saudi J Gastroenterol. 2012;4:230-6.

49. Santiago I, Loureiro R, Curvo-Semedo L, Marques C, Tardáguila $\mathrm{F}$, Matos $\mathrm{C}$, et al. Congenital cystic lesions of the biliary tree. Am J Roentgenol 2012;198:825-35.

50. Craig AG, Chen LD, Saccone GT, Chen J, Padbury RT, Toouli J. Sphincter of Oddi dysfunction associated with choledochal cyst. J Gastroenterol Hepatol 2001;16:230-4.

51. Kim MJ, Han SJ, Yoon CS, Kim JH, Oh JT, Chung KS, et al. 
Using MR cholangiopancreatography to reveal anomalous pancreaticobiliary ductal union in infants and children with choledochal cysts. Am J Roentgenol 2002;179:209-14.

52. Jang SM, Lee BS, Kim KK, Lee JN, Koo YS, Kim YS, et al. Clinical comparison of choledochal cysts between children and adults. Korean J Hepatobiliary Pancreat Surg 2011;15: 157-63.

53. Fitoz S, Erden A, Boruban S. Magnetic resonance cholangiopancreatography of biliary system abnormalities in children. Clin Imaging 2007;31:93-101.

54. Huang SG, Guo WL, Wang J, Sheng M, Lan XH, Fang L. Factors interfering with delineation on MRCP of pancreaticobiliary maljunction in paediatric patients. PLoS One 2016; 11:e0154178

55. Tipnis NA, Dua KS, Werlin SL. A retrospective assessment of magnetic resonance cholangiopancreatography in children. J Pediatr Gastroenterol Nutr 2008;46:59-64.

56. Giefer MJ, Lowe ME, Werlin SL, Zimmerman B, Wilschanski $M$, Troendle $D$, et al. Early-onset acute recurrent and chronic pancreatitis is associated with PRSS1 or CTRC gene mutations. J Pediatr 2017;186:95-100.

57. Dai LN, Chen YW, Yan WH, Lu LN, Tao YJ, Cai W. Hereditary pancreatitis of 3 Chinese children: case report and literature review. Medicine (Baltimore) 2016;95:e4604.

58. Patel J, Madan A, Gammon A, Sossenheimer M, Samadder NJ. Rare hereditary cause of chronic pancreatitis in a young male: SPINK1 mutation. Pan Afr Med J 2017;28:110.

59. Wang W, Sun XT, Weng XL, Zhou DZ, Sun C, Xia T, et al. Comprehensive screening for PRSS1, SPINK1, CFTR, CTRC and CLDN2 gene mutations in Chinese paediatric patients with idiopathic chronic pancreatitis: a cohort study. BMJ Open 2013;3:e003150.

60. Lonergan GJ, Baker AM, Morey MK, Boos SC. From the archives of the AFIP. Child abuse: radiologic-pathologic correlation. Radiographics 2003;23:811-45

61. Gupta A, Stuhlfaut JW, Fleming KW, Lucey BC, Soto JA. Blunt trauma of the pancreas and biliary tract: a multimodality imaging approach to diagnosis. Radiographics 2004;24: 1381-95.

62. Mekitarian Filho E, Carvalho WB, Silva FD. Acute pancreatitis in pediatrics: a systematic review of the literature. J Pediatr (Rio J) 2012;88:101-14.

63. Limwattana S, Dissaneewate P, Kritsaneepaiboon S, Dendumrongsup T, Vachvanichsanong P. Systemic lupus erythematosus-related pancreatitis in children. Clin Rheumatol 2013;32:913-8.

64. Carbonetti F, lannicelli E, Federici M, Bucciarelli A, Pilozzi E, Conte $\mathrm{E}$, et al. Primary pancreatic Burkitt lymphoma presenting as acute pancreatitis. J Gastrointest Cancer 2014;45(Suppl 1): S265-9.

65. Chung EM, Travis MD, Conran RM. Pancreatic tumors in children: radiologic-pathologic correlation. Radiographics 2006;26:1211-38.

66. Treepongkaruna S, Thongpak N, Pakakasama S, Pienvichit P, Sirachainan N, Hongeng S. Acute pancreatitis in children with acute lymphoblastic leukemia after chemotherapy. J Pediatr Hematol Oncol 2009;31:812-5.

67. Hijiya N, van der Sluis IM. Asparaginase-associated toxicity in children with acute Iymphoblastic leukemia. Leuk Lymphoma 2016;57:748-57.

68. Blejter J, Weller S, Pace R, Cusumano H, Giambini D. Autoimmune pancreatitis: an adolescent case and review of literature. J Pediatr Surg 2008;43:1368-72.

69. Rawla P, Bandaru SS, Vellipuram AR. Review of infectious etiology of acute pancreatitis. Gastroenterology Res 2017;10: 153-8.

70. Dutra ÁP, Sanchez Candiani TM, de Oliveira SF, Mattos FF, de Carvalho IR. Acute pancreatitis in child with relapsing hepatitis a viral infection. J Clinic Med Case Rep 2020 doi: 10.31487/J.JCMCR.2020.02.04.

71. Chandak S, Mandal A, Singh A. Acute pancreatitis and pancreatic pseudocyst in a toddler following mumps, measles and rubella vaccine. Clin Pediatr OA 2017. doi:10.4172/25720775.1000117 . 